\title{
Effects of Strength Training on Olympic Time-Based Sport Performance: A Systematic Review and Meta-Analysis of Randomized Controlled Trials
}

\author{
Danny Lum and Tiago M. Barbosa
}

\begin{abstract}
Purpose: To evaluate the effect of strength training on Olympic time-based sports (OTBS) time-trial performance and provide an estimate of the impact of type of strength training, age, training status, and training duration on OTBS time-trial performance. Methods: A search on 3 electronic databases was conducted. The analysis comprised 32 effects in 28 studies. Posttest time-trial performance of intervention and control group from each study was used to estimate the standardized magnitude of impact of strength training on OTBS time-trial performance. Results: Strength training had a moderate positive effect on OTBS time-trial performance (effect size $=0.59, P<.01)$. Subgroup meta-analysis showed that heavy weight training (effect size $=0.30, P=.01$ ) produced a significant effect, whereas other modes did not induce significant effects. Training status as factorial covariate was significant for well-trained athletes (effect size $=0.62, P=.04$ ), but not for other training levels. Meta-regression analysis yielded nonsignificant relationship with age of the participants recruited $(\beta=-0.04 ; 95 \%$ confidence interval, -0.08 to $0.004 ; P=.07)$ and training duration ( $\beta=-0.05 ; 95 \%$ confidence interval, -0.11 to $0.02 ; P=.15)$ as continuous covariates. Conclusion: Heavy weight training is an effective method for improving OTBS time-trial performance. Strength training has greatest impact on well-trained athletes regardless of age and training duration.
\end{abstract}

Keywords: running, cycling, swimming, rowing, resistance training

The performance in Olympic time-based sports (OTBS) such as long- and middle-distance running, cycling, swimming, rowing, and sprint kayaking is a multifactorial phenomenon. In such sports, energy expenditure is determined by aerobic and anaerobic pathways. ${ }^{1-4}$ Although maximum oxygen consumption and anaerobic capacity might differ between different tiers of sportsmen (eg, well trained vs elite), these physiological factors might not be good predictors among athletes of the same tier or competitive level as it yields lower variability. Conversely, movement economy displays a higher degree of variability among individuals and has been shown to be an important predictor of endurance performance. . $^{5-7}$ Movement economy can be defined as the steady-rate oxygen cost of a standard power output or movement speed. ${ }^{8,9}$ Movement economy is dependent on anthropometric features and physiologi$\mathrm{cal}$, biomechanical, and neuromuscular factors. ${ }^{10-12}$

The role of neuromuscular factors in improving movement economy and, therefore, performance in OTBS has been extensively studied in recent years. ${ }^{13-21}$ Multiple studies have been conducted to investigate the relationship between strength and OTBS performance. ${ }^{22-25}$ These studies showed that there was a moderate correlation between isometric squat peak force and running economy $(r=.57),{ }^{22}$ a moderate to large correlation between 30 -second Wingate cycling and track cycling split time with isometric midthigh pull peak force $(.78 \leq r \leq .86$ and $-.49 \leq$ $r \leq-.55$, respectively), and small to large correlation between upper-body strength and sprint kayak (200- to 1000-m) performance $(-.47 \leq r \leq-.97) .{ }^{23,25}$ Findings from these studies suggest

Lum is with Sport Science and Sport Medicine, Singapore Sport Inst, Singapore. Lum and Barbosa are with Physical Education and Sports Science, National Inst of Education, Nanyang Technological University, Singapore. Barbosa is also with the Polytechnic Inst of Braganca, Braganca, Portugal. Lum (dannylum82@gmail.com) is corresponding author. that improving the strength of muscles involved in the movement of the respective sport might lead to performance enhancement. One explanation as to why the increase in muscular strength and power might improve OTBS performance and movement economy is because, with increased strength, there would be a reduction in relative load to the working muscles and possibly more optimal activation of motoneurons. ${ }^{12}$ Thus, reducing the energy cost of movement. In addition, the reduction in relative load would also reduce the rate of local muscular fatigue so that athletes would be able to maintain an optimal movement velocity for a longer period of time, ${ }^{19}$ which would enable to achieve a faster race time.

Many studies investigating the effects of heavy weights and explosive strength have shown improved OTBS performance with increased muscular strength or power also. ${ }^{19,26-30}$ Therefore, strength training seems to be an efficient and practical method for enhancing OTBS performance. Some systematic reviews and only a few meta-analyses have provided partial evidence that strength training is beneficial to OTBS, such as endurance running, ${ }^{15-16}$ cycling, ${ }^{13-21}$ competitive swimming, ${ }^{14}$ and rowing. ${ }^{18}$ However, there is currently no systematic review on the effect of strength training on the performance of multiple OTBS within one review study and hence, enabling comparisons across sports. Moreover, there is no meta-analysis published in the literature with a metaanalysis consolidating the evidence gathered in all these OTBS, providing a wider and quantitative insight on the effects of strength training in performance.

Several factors such as age, training status, and duration of training can affect endurance performance and movement economy. ${ }^{15-16,31}$ Meta-analysis by Allen and Hopkins ${ }^{31}$ showed that there is a wide range of peak performance ages of elite athletes due to the differences in the attributes required for success in different sporting events. For example, early specialization might have allowed swimmers to acquire the efficient aquatic motion necessary 
for a successful swim; hence, the early peaking phenomenon observed in swimmers. ${ }^{31}$ By contrast, aerobic capacity and movement economy required for ultraendurance events increases progressively with increasing training history. ${ }^{31}$ Thus, this is the reason why better performing athletes in such events tend to be older. However, the impact of age on the effects of strength training on OTBS performance remains unclear. Meta-analyses by Berryman et $\mathrm{al}^{15}$ and Denadai et $\mathrm{al}^{16}$ noted that longer strength training programs resulted in greater improvements in endurance performance and running economy. Denadai et al ${ }^{16}$ showed that effects of strength training on running economy did not differ between runners of different training status. However, both studies did not report the impact of athletes' age on the effects of strength training on endurance performance. Furthermore, there is currently no meta-analysis conducted to clarify the impact of these factors (age, training status, and duration of training program) on how strength training affects performance in other OTBS.

The main aim of this study was to systematically review the current body of knowledge on the effects of strength training on OTBS time-trial performance (ie, endurance running, cycling, swimming and rowing). The second aim was to conduct a metaanalysis providing an estimate of the contributions by several factors to the improvement in OTBS time-trial performance (such as age, training status, and duration of training program).

\section{Methods}

\section{Literature Search}

A systematic search of randomized controlled trials on the effects of strength training on OTBS time-trial performance was conducted. Original research and review articles up to December 28, 2018 were searched and retrieved from electronic searches on PubMed, SPORTDiscus, and Google Scholar databases. PICO (P-patient, problem, or population; I-intervention; C-comparison, control, or comparator; $\mathrm{O}$-outcomes) search strategy was conducted based on the Boolean technique presented in Table 1.

\section{Inclusion and Exclusion Criteria}

Figure 1 depicts the PRISMA flow diagram identifying, screening, checking eligibility, and inclusion of the studies. Studies were considered for review if they met the following inclusion criteria: (1) randomized controlled trials, (2) available in English, (3) studies which included time trial of an OTBS as performance measure, and (4) studies that included any modes of strength training (including isotonic, isometric, isokinetic, plyometric, variable resistance, and calisthenics). Studies were excluded for the following reasons:
(1) not randomized controlled trials, (2) reported only physiological measures and no performance outcome, and (3) participants were not at least recreational athletes of the respective sports.

\section{Study Selection}

Eighty-five relevant studies were retained from the search of the electronic databases and examination of the reference lists. Fortyone articles were excluded based on study design $(n=9)$, studies were off topic $(n=11)$, studies were either reviews or book chapters $(n=18)$, and studies were not written in English $(n=3)$. Forty-four articles were read in full and 28 articles were included in the meta-analysis (Figure 1).

\section{Quality of the Studies}

Quality of the 28 studies included were assessed based on the Physiotherapy Evidence-Based Database (PEDro) scale as this method of assessment has been shown to be reliable for rating quality of randomized controlled trials. ${ }^{32}$ In addition, previous systematic reviews and meta-analysis have also used this method to assess the quality of studies that investigated on the effects of strength training on endurance sports. ${ }^{16,21}$ The scale pertains to the internal validity and data analysis of a research study. Maximal total score is 11 points, with higher scores indicating better quality. Components of the PEDro scale include (1 point per item): (1) eligibility criteria were specified; (2) subjects were randomly allocated to groups; (3) allocation was concealed; (4) groups were similar at baseline regarding the most important prognostic indicators; (5) blinding of all subjects; (6) blinding of all therapists who administered the therapy; (7) blinding of all assessors who measured at least 1 key outcome; (8) measures of at least 1 key outcome were obtained from more than $85 \%$ of the subjects initially allocated to the groups; (9) all subjects for whom outcome measures were available received the treatment or control condition as allocated or, where this was not the case, data for at least 1 key outcome was analyzed by "intention to treat"; (10) results of between-group statistical comparisons are reported for at least 1 key outcome; and (11) the study provides both point measures and measures of variability for at least 1 key outcome.

\section{Characteristics of Studies Included}

Thirty training effects from 28 studies were included in the metaanalysis. The scope of these studies is summarized in Table 2. Total number of subjects in these 28 studies was 568 (310 assigned to experimental groups and 258 to control groups). Subjects were recreational, well trained, highly trained, and adolescents in 4, 12,

Table 1 PICO Process and Boolean Search Technique

\begin{tabular}{llll}
\hline Population & Intervention & Comparison (ie, design) & Outcome \\
\hline Human* & Strength training & Randomized controlled trial & Performance \\
Subject* & Resistance training & & Time trial \\
Athlete* & Concurrent training & & Power \\
Participant* & Plyometric training & & Velocity \\
Male* & & & Economy \\
Female* & & & Running \\
Adolescent* & & & Cycling \\
& & & Rowing \\
& & Kayaking \\
& & Swimming \\
\hline
\end{tabular}

Note: Asterisks denote truncation to retrieve words with different endings. 


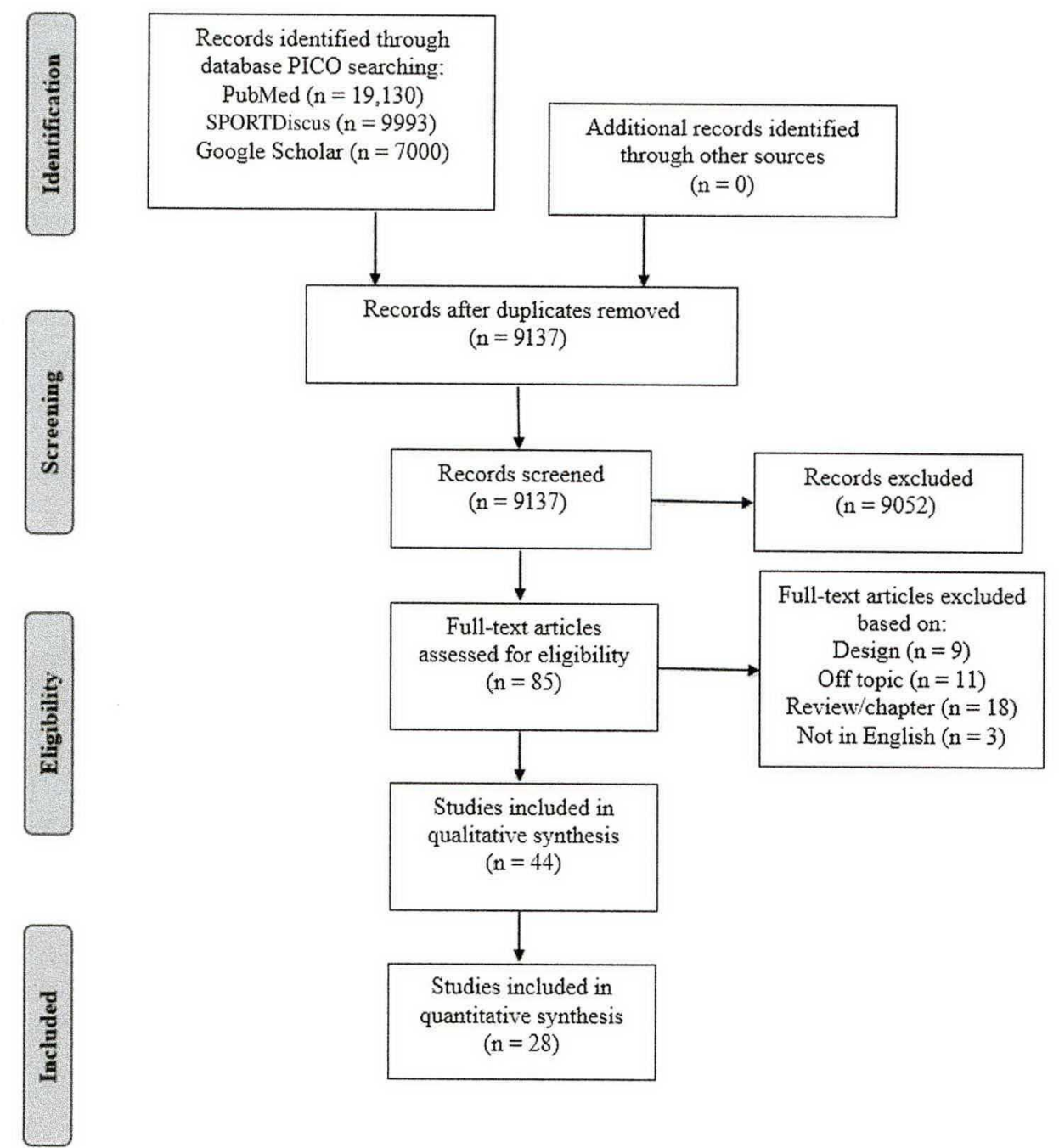

Figure 1 - Summary of PRISMA flow for search strategy.

7, and 5 studies, respectively. Subjects were categorized into respective training status based on the description stated by the authors of each study. Subjects in "recreational" included those described as recreational, "well trained" included those described as well trained or competitive, "highly trained" included those described as highly trained and elite, and adolescents included those below the age of 18 years old. It was assessed running, cycling, swimming, and rowing in 10, 10, 8, and 1 of the studies, respectively. Type of strength training selected included heavy weights training (HWT), plyometric training (PT), endurance weights training (EWT) and mixed heavy weights, and plyometric training (HPT) in 15, 10, 4, and 2 studies, respectively (Table 3).

\section{Data Analysis}

All data are reported as mean $\pm 95 \%$ confidence interval $(\mathrm{CI})$. The posttest time-trial running, swimming, and rowing velocity, and cycling average power, of intervention and control group from each study was used to estimate the standardized magnitude of impact of strength training on OTBS time-trial performance. Better time-trial performance is represented by faster running, swimming, and rowing velocity, and higher cycling average power. The weight of each study was computed as variance of the posttest velocity and average power.

A random effect model (restricted maximum likelihood) was selected because of the wide variation in experimental factor levels in the studies included for synthesis and analysis. Hedges' $g$ was selected as standardized effect size (ES). Statistical heterogeneity was assessed by Cochran's $Q$ and $I^{2} . I^{2}$ of $25 \%, 50 \%$, and $70 \%$ are deemed as low, medium, and high level of heterogeneity, respectively. ${ }^{55}$ Subgroup meta-analysis was performed for factorial covariates including training status and type of strength training. Metaregression analysis was performed for continuous covariates including age of participants and duration of intervention. The statistics of the full model reflect the combined impact of all covariates, whereas statistic of individual covariate reflects the impact of the specific covariate. The standardized magnitude of training induced changes was deemed as ${ }^{56}$ : (1) trivial ES, if $0 \leq 1$ $\mathrm{ES} \mid \leq 0.2$; (2) small sizes, if $0.2<|\mathrm{ES}| \leq 0.5$; (3) moderate sizes, if $0.5<|\mathrm{ES}| \leq 0.8$; and (4) large sizes, if $|\mathrm{ES}|>0.8$. Data analyses were run on $\mathrm{R}$ (metaphor, ggplot2, and OpenMeta packages) $(P<.05)$.

\section{Results}

\section{Quality of the Studies}

The quality of the 28 studies was very similar, with PEDro scores ranging from 5 to 7 (Table 2). All 28 studies did not meet the criteria for the following components: (1) allocation was concealed, (2) blinding of all subjects, (3) blinding of all researchers who administered the intervention program, and (4) blinding of all assessors who measured 
Table 2 Characteristics of Studies Included in the Meta-analysis

\begin{tabular}{|c|c|c|c|c|c|}
\hline Authors & Mode & $\mathrm{N}$ & Sex & Training status & PEDro scale \\
\hline Aagaard et $\mathrm{al}^{26}$ & Cycling & 14 & $\mathrm{M}$ & Highly trained & 6 \\
\hline Amaro et $\mathrm{al}^{27}$ & Swimming & 21 & $\mathrm{~F}$ and $\mathrm{M}$ & Adolescent & 7 \\
\hline Aspenes et $\mathrm{al}^{33}$ & Swimming & 20 & $\mathrm{~F}$ and $\mathrm{M}$ & Adolescent & 7 \\
\hline Bastiaans et $\mathrm{al}^{34}$ & Cycling & 14 & M & Well trained & 6 \\
\hline Berryman et $\mathrm{al}^{35}$ & Running & 35 & M & Well trained & 6 \\
\hline Bishop et $\mathrm{al}^{36}$ & Cycling & 21 & F & Well trained & 6 \\
\hline Bishop et $\mathrm{al}^{37}$ & Swimming & 22 & $\mathrm{~F}$ and $\mathrm{M}$ & Adolescent & 7 \\
\hline Cossor et $\mathrm{al}^{38}$ & Swimming & 38 & $\mathrm{~F}$ and $\mathrm{M}$ & Adolescent & 6 \\
\hline Damasceno et al $^{39}$ & Running & 18 & M & Recreational & 5 \\
\hline Gallagher et $\mathrm{al}^{17}$ & Rowing & 18 & M & Well trained & 7 \\
\hline Garrido et al ${ }^{40}$ & Swimming & 25 & $\mathrm{~F}$ and $\mathrm{M}$ & Adolescent & 7 \\
\hline Girold et $\mathrm{al}^{28}$ & Swimming & 24 & $\mathrm{~F}$ and $\mathrm{M}$ & Well trained & 6 \\
\hline Karsten et al ${ }^{41}$ & Running & 16 & $\mathrm{~F}$ and $\mathrm{M}$ & Recreational & 7 \\
\hline Kelly et $\mathrm{al}^{42}$ & Running & 16 & F & Recreational & 6 \\
\hline Naczk et $\mathrm{al}^{43}$ & Swimming & 14 & M & Well trained & 7 \\
\hline Paavolainen et $\mathrm{al}^{29}$ & Running & 22 & M & Highly trained & 6 \\
\hline Paton and Hopkins ${ }^{44}$ & Cycling & 18 & M & Well trained & 6 \\
\hline Pellegrino et $\mathrm{al}^{45}$ & Running & 22 & $\mathrm{~F}$ and $\mathrm{M}$ & Well trained & 6 \\
\hline Potdevin et $\mathrm{al}^{46}$ & Swimming & 23 & $\mathrm{~F}$ and $\mathrm{M}$ & Adolescent & 7 \\
\hline Psilander et $\mathrm{al}^{47}$ & Cycling & 19 & M & Well trained & 7 \\
\hline Ramirez-Campillo et al ${ }^{48}$ & Running & 36 & $\mathrm{~F}$ and $\mathrm{M}$ & Highly trained & 7 \\
\hline Rønnestad et al ${ }^{49}$ & Cycling & 20 & $\mathrm{~F}$ and $\mathrm{M}$ & Well trained & 6 \\
\hline Rønnestad et $\mathrm{al}^{30}$ & Cycling & 12 & $\mathrm{~F}$ and $\mathrm{M}$ & Well trained & 7 \\
\hline Rønnestad et $a^{50}$ & Cycling & 20 & $\mathrm{~F}$ and $\mathrm{M}$ & Highly trained & 6 \\
\hline Schumann et $\mathrm{al}^{51}$ & Running & 27 & M & Recreational & 7 \\
\hline Vikmoen et $\mathrm{al}^{52}$ & Cycling & 19 & $\mathrm{~F}$ & Well trained & 7 \\
\hline Vikmoen et al ${ }^{53}$ & Running and cycling & 19 & $\mathrm{~F}$ & Well trained & 7 \\
\hline Vorup et $\mathrm{al}^{54}$ & Running & 16 & M & Well trained & 6 \\
\hline
\end{tabular}

Abbreviations: F, female; M, male; PEDro, Physiotherapy Evidence-Based Database.

at least one key outcome. Thirteen of the studies did not include eligibility criteria, and 2 studies did not have more than $85 \%$ of subjects originally assigned to groups completing the studies.

\section{Effect of Strength Training on Time-Trial Performance}

Twenty of the 30 training effects showed improved time-trial performance. The standardized ES of strength training on timetrial performance ranged from -0.81 to 8.74 (Figure 2). Overall, strength training had a moderate positive effect on OTBS time-trial performance (ES $=0.59 ; 95 \% \mathrm{CI}, 0.22$ to $0.96 ; Q=112.04 ; I^{2}=$ $72 \% ; P<.01)$. At least 2 studies fell beyond the funnel tunnel of the plot SEs versus standardized mean differences. Removing these 2 studies, the meta-analysis yielded an ES $=0.46$ and $I^{2}=62 \%$. Therefore, an effect of strength training on performance was noted. Further analysis was required to better understand the high heterogeneity $\left(I^{2}=72 \%\right)$ of the full data set.

\section{The Effect of Training Status and Training Type}

The results of the subgroup meta-analysis having training status as factorial covariate was significant for well-trained athletes $(\mathrm{ES}=$ $0.62 ; 95 \% \mathrm{CI}, 0.02$ to $1.22 ; P=.04)$. It was nonsignificant for recreational athletes ( $\mathrm{ES}=0.21 ; 95 \% \mathrm{CI},-0.24$ to $0.65 ; P=.37$ ), highly trained athletes ( $\mathrm{ES}=0.47 ; 95 \% \mathrm{CI},-0.03$ to $0.97 ; P=.06$ ), and adolescents $(\mathrm{ES}=1.61 ; 95 \% \mathrm{CI},-0.88$ to $4.10 ; P=.20)$, albeit moderate to large effects in some cohorts (Figure $3 \mathrm{~A}$ ).

Comparing the training type, subgroup meta-analysis was significant for HWT (ES $=0.30 ; 95 \% \mathrm{CI}, 0.07$ to $0.53 ; P=.01$ ). It was nonsignificant for PT (ES $=1.49 ; 95 \% \mathrm{CI},-0.21$ to 3.19 ; $P=.09)$, EWT $(\mathrm{ES}=0.99 ; 95 \% \mathrm{CI},-1.96$ to $3.95 ; P=.51)$, and HPT (ES $=0.82 ; 95 \% \mathrm{CI},-0.87$ to $2.51 ; P=.34$ ), despite again moderate to large effects were noted (Figure 4).

\section{The Effect of Age and Training Duration}

Meta-regression analysis yielded a nonsignificant relationship with age of the participants recruited $(\beta=-0.04 ; 95 \% \mathrm{CI},-0.08$ to $0.004 ; P=.07)$ and training duration $(\beta=-0.05 ; 95 \% \mathrm{CI},-0.11$ to $0.02 ; P=.15$ ) as continuous covariates. Therefore, training status, age of participants, and training duration have no significant impact on the effects of strength training on OTBS time-trial performance.

\section{Discussion}

The purpose of this meta-analysis was to evaluate the effects of strength training on OTBS time-trial performance and estimate 


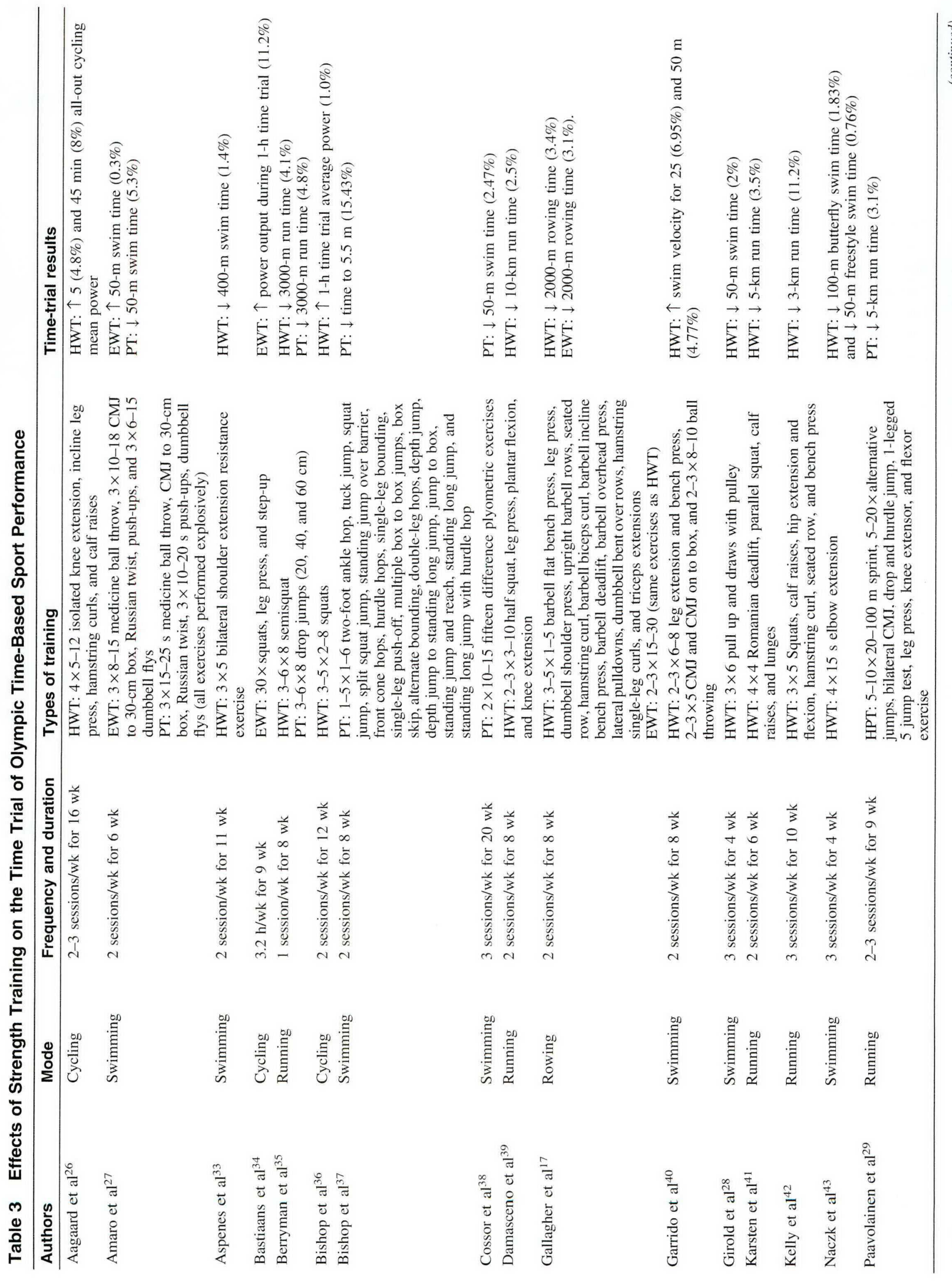




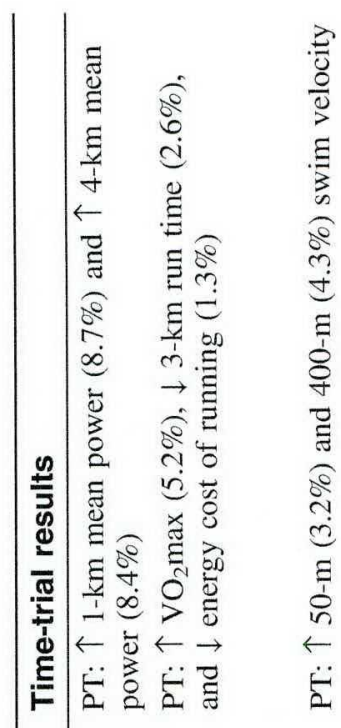

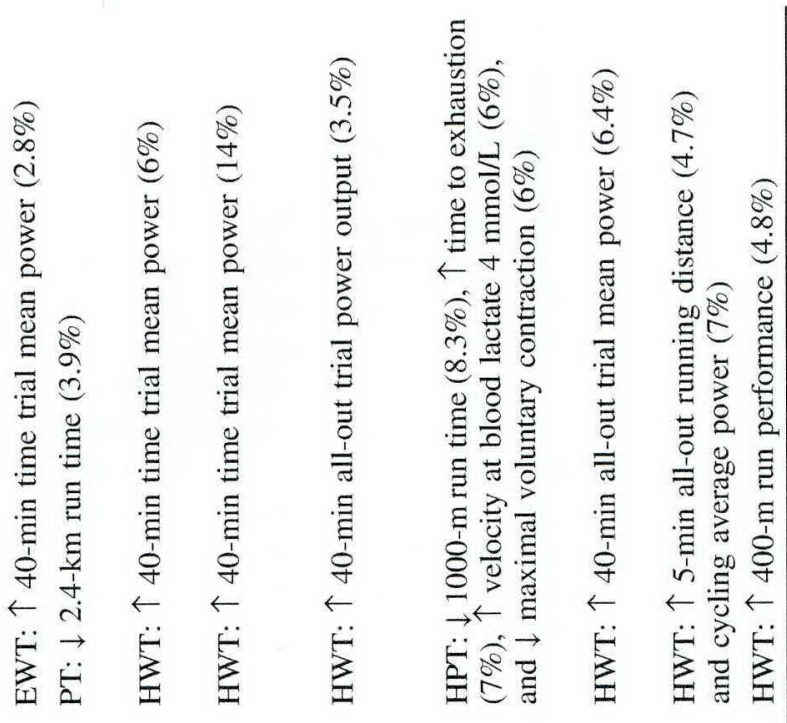

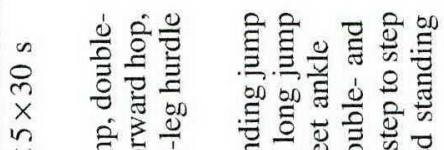

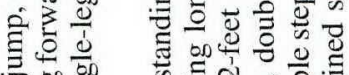

की

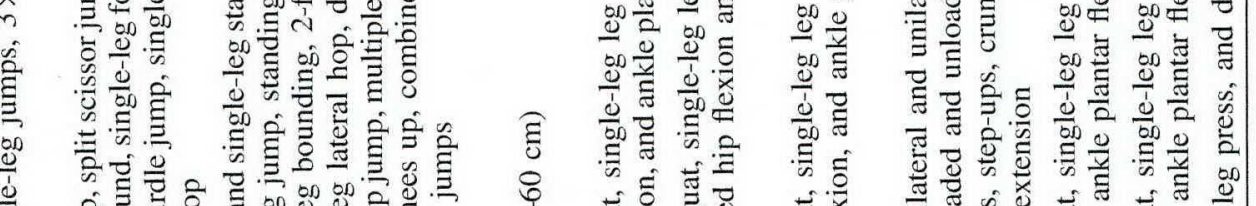

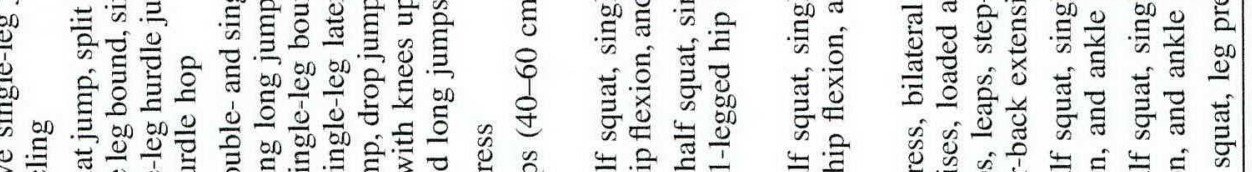

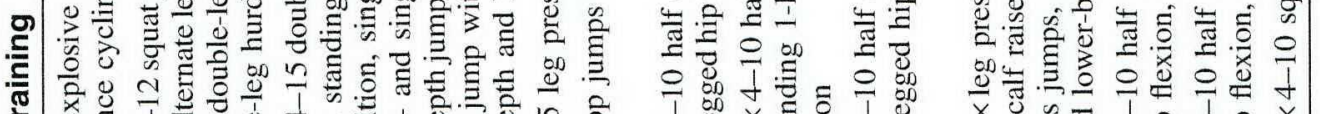

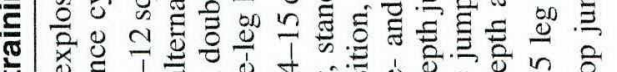

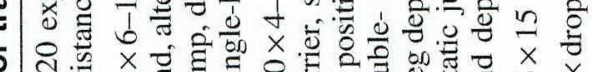

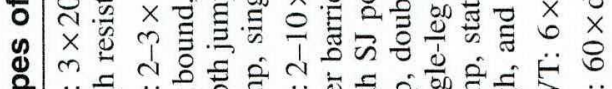

에

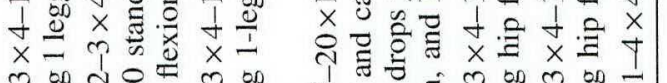

m

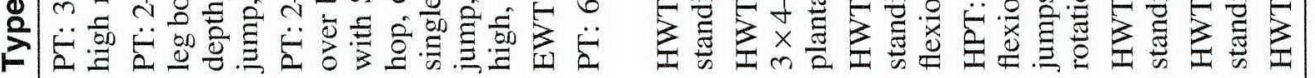

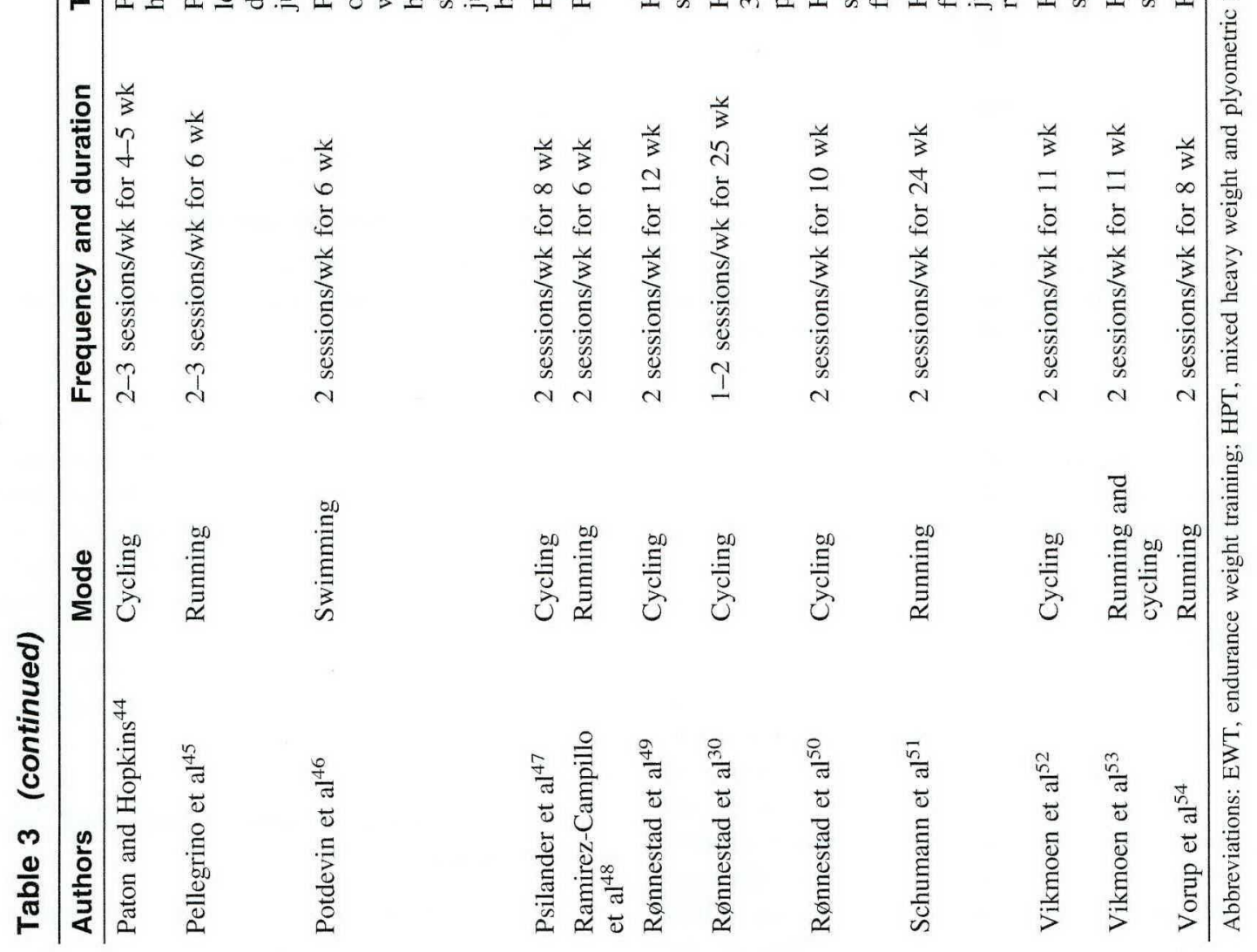




\begin{tabular}{|c|c|c|c|}
\hline Studies & Est: & imate $195 \%$ & CI) \\
\hline Aagaard et $\mathrm{al}^{26}$ & 0.658 & $(-0.418$ to & $1.734)$ \\
\hline Amaro et $\mathrm{al}^{27}$ & -0.179 & $(-1.229$ to & $0.870)$ \\
\hline Amaro et $\mathrm{al}^{27}$ & 0.673 & $(-0.404$ to & $1.750)$ \\
\hline Aspenes et $\mathrm{al}^{33}$ & 0.275 & $(-0.610$ to & $1.160)$ \\
\hline Bastiaans et al ${ }^{34}$ & -0.808 & $(-1.908$ to & $0.292)$ \\
\hline Berryman et $\mathrm{al}^{35}$ & -0.414 & $(-1.481$ to & $0.653)$ \\
\hline Berryman et al $^{35}$ & -0.274 & $(-1.321$ to & $0.774)$ \\
\hline Bishop et $\mathrm{al}^{36}$ & -0.215 & $(-1.124$ to & $0.695)$ \\
\hline Bishop et al $^{37}$ & 1.323 & 10.400 to & $2.246)$ \\
\hline Cossor et al ${ }^{38}$ & 0.003 & $(-0.633$ to & $0.639)$ \\
\hline Damasceno et $\mathrm{al}^{39}$ & 0.485 & $(-0.453$ to & $1.422)$ \\
\hline${\text { Gallagher et } \mathrm{al}^{17}}^{17}$ & 2.790 & (1.200 to & $4.379)$ \\
\hline Gallagher et al ${ }^{17}$ & 6.120 & (3. 423 to & $8.817)$ \\
\hline Garrido et al $^{40}$ & 0.143 & $(-0.676$ to & $0.963)$ \\
\hline Girold et $\mathrm{al}^{28}$ & 1.033 & $(-0.011$ to & $2.076)$ \\
\hline Karsten et $\mathrm{al}^{41}$ & 0.151 & $(-0.830$ to & $1.133)$ \\
\hline Kelly et al ${ }^{42}$ & 0.301 & $(-0.692$ to & $1.294)$ \\
\hline Naczk et $a^{43}$ & 1.820 & $(0.574$ to & $3.065)$ \\
\hline Paavolainen et al ${ }^{29}$ & 1.727 & 10.640 to & $2.815)$ \\
\hline Paton and Hopkins ${ }^{44}$ & 0.677 & $(-0.273$ to & $1.627)$ \\
\hline Pellegrino et $a^{45}$ & 1.699 & 10.724 to & $2.674)$ \\
\hline Potdevin et al ${ }^{46}$ & 8.741 & (6.086 to & 11.396) \\
\hline Psilander et $\mathrm{al}^{47}$ & -0.362 & $(-1.270$ to & $0.545)$ \\
\hline Ramirez-Campillo et al ${ }^{48}$ & 0.782 & 10.104 to & $1.459)$ \\
\hline Ronnestad et al ${ }^{49}$ & 0.284 & $(-0.601$ to & $1.170)$ \\
\hline Ronnestad et $\mathrm{al}^{30}$ & 0.608 & $(-0.549$ to & $1.766)$ \\
\hline Ronnestad et al ${ }^{50}$ & -0.419 & $(-1.323$ to & $0.485)$ \\
\hline Schumann et $\mathrm{al}^{51}$ & 0.000 & $(-0.755$ to & $0.755)$ \\
\hline Vikmoen et al ${ }^{52}$ & -0.155 & $(-1.067$ to & $0.757)$ \\
\hline Vikmoen et al ${ }^{53}$ & -0.097 & $(-1.009$ to & $0.814)$ \\
\hline Vikmoen et al ${ }^{53}$ & 0.371 & $(-0.547$ to & $1.290)$ \\
\hline Vorup et $\mathrm{al}^{54}$ & 0.319 & $(-0.675$ to & 1.313) \\
\hline Overall $\left(I^{2}=77.18 \%, P<.001\right)$ & 0.590 & (0.224 to & $0.957)$ \\
\hline
\end{tabular}

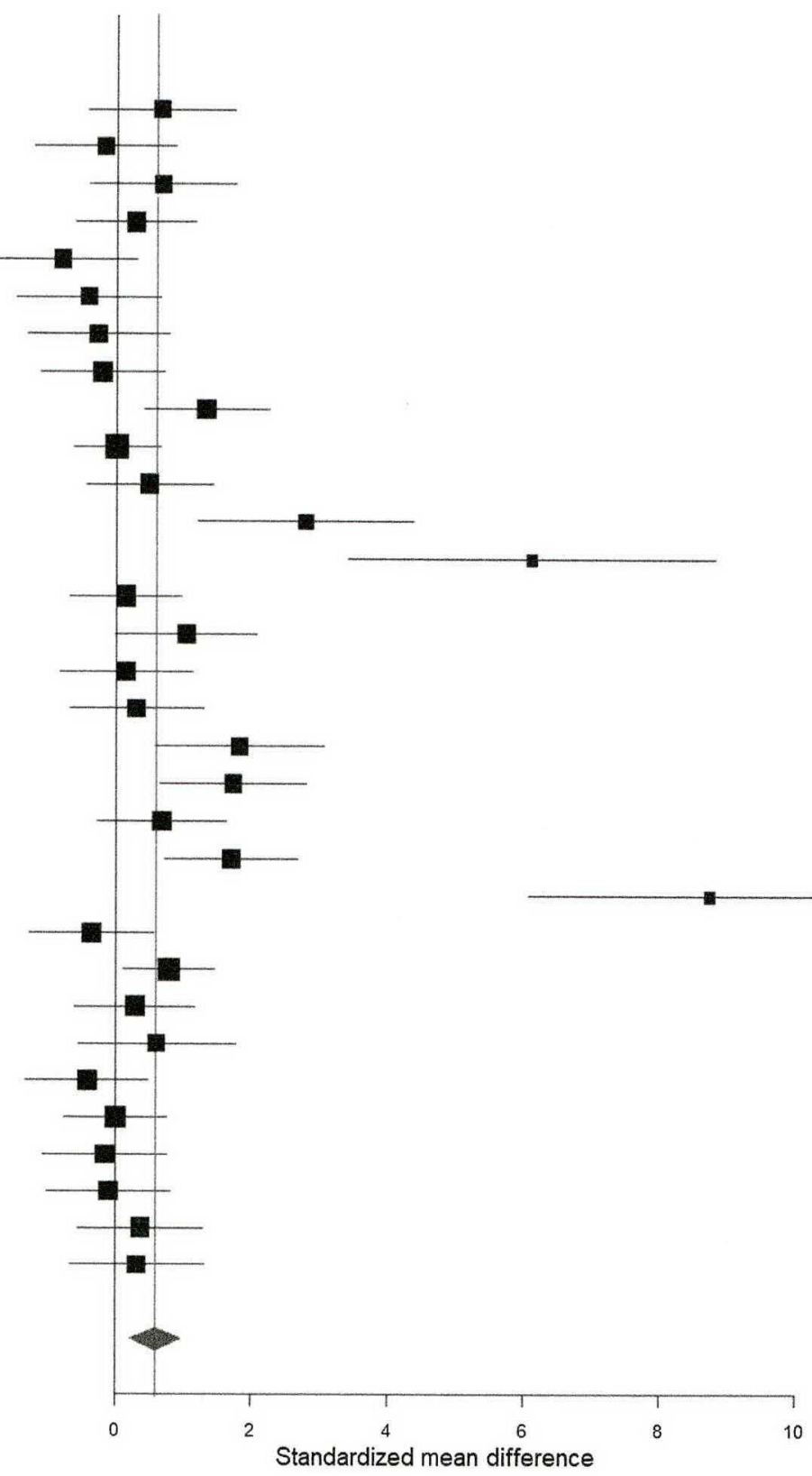

Figure 2 - Standardized mean differences of posttest time-trial performances between intervention and control groups of all included studies expressed as Hedges $g$ and 95\% CI. CI indicates confidence interval.

the contributions of age, training status, and duration of training program to the improvement in OTBS performance. There is a moderate effect of strength training on time-trial performance of OTBS. Training status, age of participants, and training duration have trivial effects.

\section{Quality of the Studies}

The PEDro quality for the 28 studies was $6.46 \pm 0.57$ and ranged from 5 to 7 (Table 2). The criteria that all studies did not fulfill were concealing of group allocation, blinding of all subjects to intervention, blinding of all researchers who administered the intervention program, and blinding of all assessors who measured at least one key outcome. As these studies involved performance of physical activities, it is challenging to conceal the group allocation and blinding the subjects and researchers to the intervention program. However, it is possible to blind the assessors who conduct the tests (if the study involves more than one investigator). Therefore, in view of this, the quality of the research methodologies of the 28 studies is considered acceptable. That said, even not considering the 3 abovementioned items, studies had room to improve the research design from an average of 6.46 \pm 0.57 to at least 8 scores. For instance, future research designs should consider finding ways of blinding the assessors who conduct the tests, clearly note eligibility criteria in the article, and tackle issues with dropout rates.

\section{Effect of Strength Training on Time-Trial Performance}

Our data showed that strength training has a moderate effect (ES = 0.65 ) on time-trial performance as compared with OTBS sports 
Studies

Aagaard et $\mathrm{al}^{26}$
Paavolainen et $\mathrm{al}^{29}$
Ramirez-Campillo et $\mathrm{al}^{48}$
Ronnestad et $\mathrm{al}^{49}$
Ronnestad et $\mathrm{al}^{30}$
Ronnestad et $\mathrm{al}^{50}$
Vikmoen et al
Subgroup highly trained $\left(I^{2}=49.38 \%, P=.067\right)$

Amaro et $\mathrm{al}^{27}$

Amaro et $\mathrm{al}^{27}$

Bishop et $\mathrm{al}^{37}$

Cossor et $\mathrm{al}^{38}$

Garrido et al $^{40}$

Potdevin et al ${ }^{46}$

Subgroup adolescents $\left(I^{2}=97.47 \%, P=.000\right)$

Aspenes et $\mathrm{al}^{33}$

Bastiaans et $\mathrm{al}^{34}$

Berryman et al ${ }^{35}$

Berryman et a ${ }^{35}$

Bishop et al ${ }^{36}$

Gallagher et $\mathrm{al}^{17}$

Gallagher et al ${ }^{17}$

Girold et al ${ }^{28}$

Naczk et al ${ }^{43}$

Paton and Hopkins ${ }^{44}$

Pellegrino et $\mathrm{al}^{45}$

Psilander et $\mathrm{al}^{47}$

Vikmoen et al ${ }^{53}$

Vikmoen et al ${ }^{53}$

Vorup et $\mathrm{al}^{54}$

Subgroup well trained $\left(I^{2}=79.27 \%, P=.000\right)$

Damasceno et $\mathrm{al}^{39}$

Karsten et al ${ }^{41}$

Kelly et $\mathrm{al}^{42}$

Schumann et $a^{51}$

Subgroup recreational $\left(I^{2}=0 \%, P=.880\right)$

Overall $\left(I^{2}=77.18 \%, P=.000\right)$
Estimate $(95 \% \mathrm{CI})$

$0.658(-0.418$ to 1.734$)$

$1.727 \quad(0.640$ to 2.815$)$

$0.782 \quad(0.104$ to 1.459$)$

$0.284(-0.601$ to 1.170$)$

$0.608(-0.549$ to 1.766$)$

$-0.419(-1.323$ to 0.485$)$

-0.155 ( -1.067 to 0.757$)$

$0.469 \quad(-0.029$ to 0.966$)$

$-0.179(-1.229$ to 0.870$)$

$0.673(-0.404$ to 1.750$)$

$1.323(0.400$ to 2.246$)$

$0.003(-0.633$ to 0.639$)$

$0.143 \quad(-0.676$ to 0.963$)$

$8.741 \quad$ (6.086 to 11.396$)$

$1.609(-0.878$ to 4.097$)$

$0.275(-0.610$ to 1.160$)$

$-0.808(-1.908$ to 0.292$)$

$-0.414 \quad(-1.481$ to 0.653$)$

$-0.274(-1.321$ to 0.774$)$

$-0.215(-1.124$ to 0.695$)$

$2.790 \quad$ (1.200 to 4.379$)$

$6.120 \quad(3.423$ to 8.817$)$

$1.033(-0.011$ to 2.076$)$

$1.820 \quad(0.574$ to 3.065$)$

$0.677(-0.273$ to 1.627$)$

$1.699 \quad(0.724$ to 2.674$)$

$-0.362(-1.270$ to 0.545$)$

$-0.097(-1.009$ to 0.814$)$

$0.371(-0.547$ to 1.290$)$

$0.319 \quad(-0.675$ to 1.313$)$

$0.619 \quad(0.018$ to 1.220$)$

$0.485(-0.453$ to 1.422$)$

$0.151 \quad(-0.830$ to 1.133$)$

$0.301(-0.692$ to 1.294$)$

$0.000 \quad(-0.755$ to 0.755$)$

$0.205 \quad(-0.245$ to 0.655$)$

$0.590 \quad(0.224$ to 0.957$)$
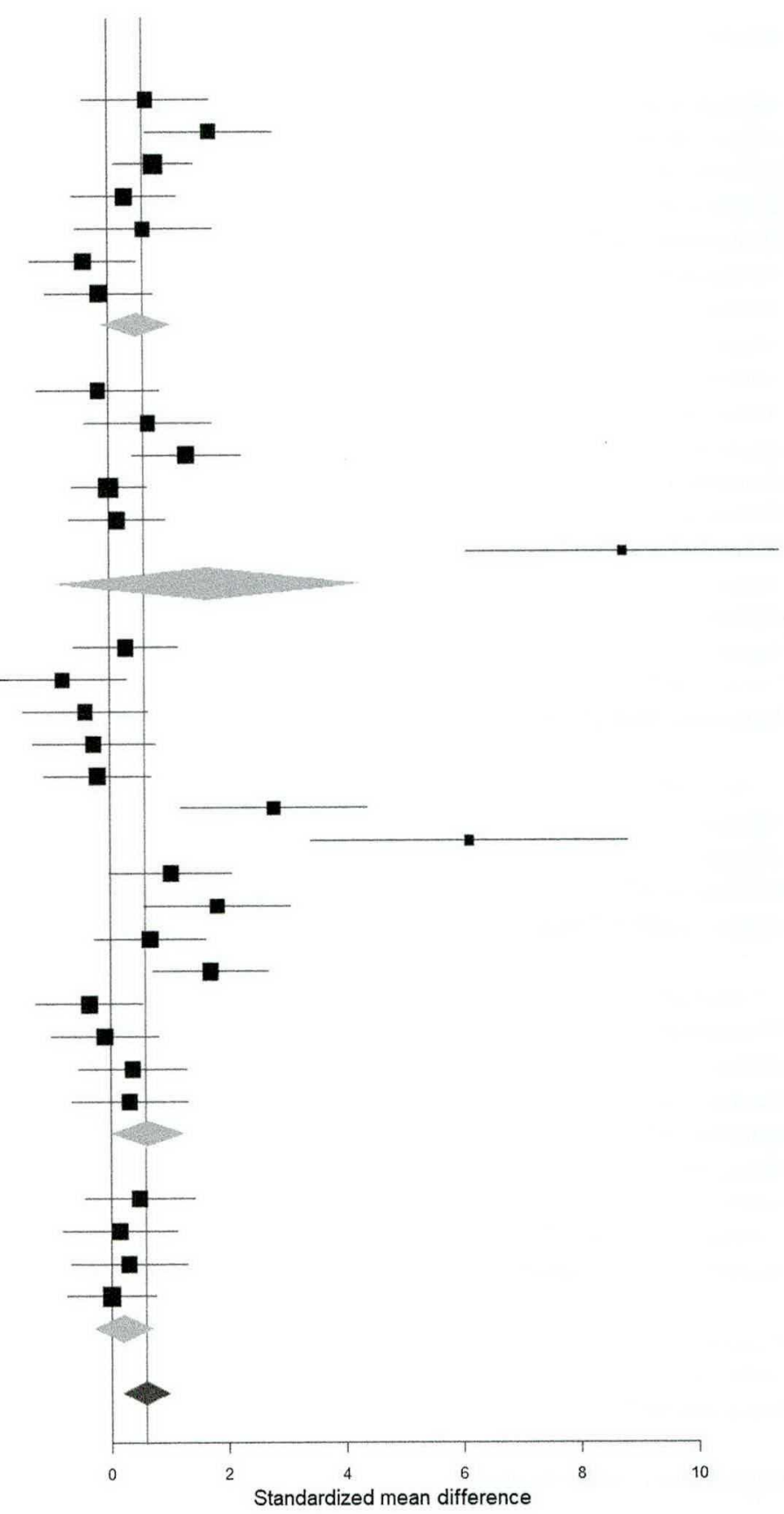

Figure 3 - Subgroup meta-analysis for training status. CI indicates confidence interval.

training alone. However, 2 studies resulted in extreme values. ${ }^{17,46}$ When these 2 studies were removed, the meta-analysis resulted in a slightly smaller effect $(\mathrm{ES}=0.46)$ but much lower heterogeneity $\left(I^{2}=62 \%\right)$. It has become a standard procedure in sport sciences and elite performance to have a goal for an improvement of at least $\mathrm{ES}=0.2 .{ }^{57}$ Practitioners, analysts, and academics in these scientific fields assume that an ES $\geq 0.2$ is already meaningful, with an impact on the athletes' performance. Therefore, an ES $=0.65$ (and even $\mathrm{ES}=0.46$ ) is deemed as very impactful.

Converting an $\mathrm{ES}=0.65$ into percentile gain, it yields an improvement of 24 points. Likewise, an $\mathrm{ES}=0.46$ yields an improvement of 18 percentile points. Let's assume that an athlete is ranked 50th in the world's top 100. After going under a strength training program, one can expect that the athlete will move up to rank 24th (if $\mathrm{ES}=0.65$ ) or 32 nd (if $\mathrm{ES}=0.46$ ). As such, strength training has a meaningful impact on the performance of OTBS.

A possible reason for the large ES observed in the studies by Gallagher et $\mathrm{al}^{17}$ and Potdevin et $\mathrm{al}^{46}$ is the difference in preintervention rowing velocity and diving velocity, respectively, between the intervention and control groups. In both studies, the preintervention and postintervention performances of intervention groups were better than the postintervention performance of the control groups. However, both studies did not report any significant difference in preintervention performance between groups. Improvement to the methodology of the studies could be accomplished by matching subjects for performance level prior to randomly assigning them to different groups (ie, selecting a counter-balanced randomized research design). 


\section{Studies}

Aagaard et al ${ }^{26}$

Aspenes et al ${ }^{33}$

Berryman et $\mathrm{al}^{35}$

Bishop et al ${ }^{36}$

Damasceno et al ${ }^{39}$

Gallagher et $\mathrm{al}^{17}$

Garrido et al ${ }^{40}$

Girold et $\mathrm{al}^{28}$

Karsten et al ${ }^{41}$

Kelly et al ${ }^{42}$

Naczk et al ${ }^{43}$

Ronnestad et al $^{49}$

Ronnestad et al ${ }^{30}$

Ronnestad et $\mathrm{al}^{50}$

Vikmoen et al $^{52}$

Vikmoen et al ${ }^{53}$

Vikmoen et al $^{53}$

Vorup et al $^{54}$

Subgroup HWT $\left(I^{2}=1.29 \%, P=.103\right)$

Amaro et $a^{27}$

Bastiaans et $\mathrm{al}^{34}$

Gallagher et $a^{17}$

Psilander et al ${ }^{47}$

Subgroup EWT $\left(I^{2}=95.82 \%, P=.000\right)$

Amaro et $\mathrm{al}^{27}$

Berryman et al ${ }^{35}$

Bishop et al ${ }^{37}$

Cossor et al ${ }^{38}$

Paton and Hopkins ${ }^{44}$

Pellegrino et $\mathrm{al}^{45}$

Potdevin et al ${ }^{46}$

Ramirez-Campillo et al ${ }^{48}$

Subgroup PT $\left(I^{2}=96.24 \%, P=.000\right)$

Paavolainen et al ${ }^{29}$

Schumann et $\mathrm{al}^{51}$

Subgroup HPT $\left(I^{2}=84.71 \%, P=.011\right)$

Overall $\left(I^{2}=77.18 \%, P=.000\right)$
Estimate $(95 \% \mathrm{CI})$

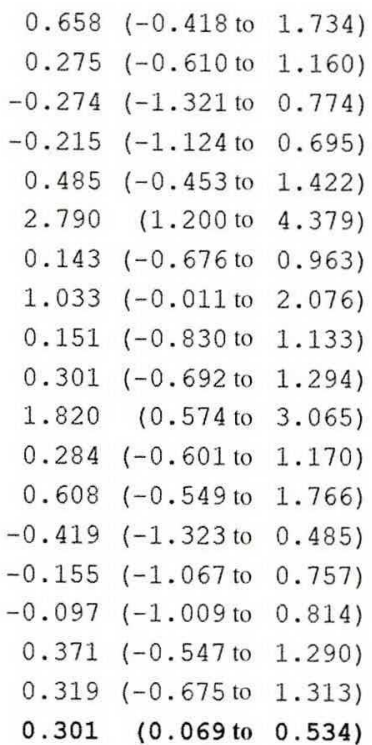

$-0.179(-1.229$ to 0.870$)$

$-0.808 \quad(-1.908$ to 0.292$)$

6.120 (3.423 to 8.817 )

$-0.362(-1.270$ to 0.545$)$

$0.992(-1.962$ to 3.947$)$

$0.673(-0.404$ to 1.750$)$

$-0.414 \quad(-1.481$ to 0.653$)$

$1.323 \quad(0.400$ to 2.246$)$

$0.003(-0.633$ to 0.639$)$

$0.677(-0.273$ to 1.627$)$

$1.699 \quad(0.724$ to 2.674$)$

$8.741 \quad$ (6.086 to 11.396$)$

$0.782 \quad(0.104$ to 1.459$)$

$1.490(-0.215$ to 3.194$)$

$1.727 \quad(0.640$ to 2.815$)$

$0.000 \quad(-0.755$ to 0.755$)$

$0.817(-0.873$ to 2.508$)$

$0.590 \quad(0.224$ to 0.957$)$

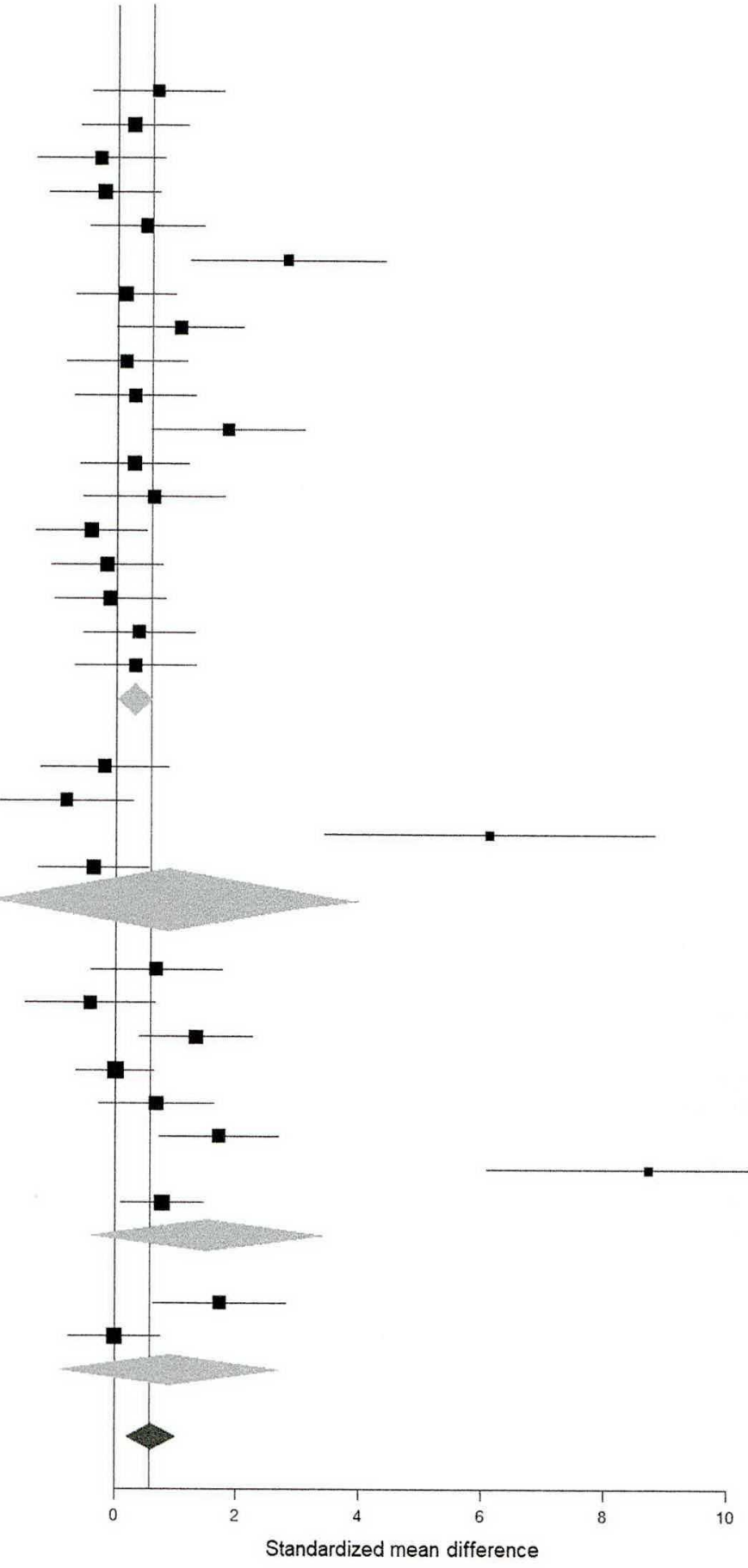

Figure 4 - Subgroup meta-analysis for training type. CI indicates confidence interval.

\section{The Effect of Training Status and Training Type}

Subgroup analysis was performed to consider the effects of training status and training type. The results showed that training status has no significant impact on the effects of strength training on OTBS time-trial performance. However, HWT presented a significant small ES on OTBS time-trial performance.

Our meta-analysis showed a trend for a small effect for the highly trained athletes ( $\mathrm{ES}=0.47, P=.06$ ). Again, an $\mathrm{ES}=0.47$ yields an improvement of 18 percentile points. This finding was somewhat in tandem with Denadai et $a^{16}$ findings, which showed that improvement in running economy after concurrent strength and endurance training was similar in individuals of different training levels. Highly trained OTBS athletes could be less responsive to their specific sports training and would require higher volume or duration to make similar magnitude of improvement in time-trial performance or movement economy as athletes of lower-training status. ${ }^{58}$ However, highly trained OTBS athletes might not necessarily have more experience in strength training than athletes of lower-training status, as their training regime might include little or no strength training. ${ }^{13}$ Hence, the addition of new training stimulus such as strength training could enhance their neuromuscular adaptations to similar magnitude as compared with athletes of lower-training status; thus, improving their time-trial performance. 
It has been shown that better trained athletes have improved movement economy and are less responsive to similar training program than athletes of lower-training status. ${ }^{58}$ Results from our meta-analysis partially supported this statement, as there is significant moderate effect on the improvement in OTBS performance of well-trained athletes as compared with highly trained athletes, but not for recreational and adolescent athletes. The nonsignificant effect in recreational and adolescents could be because these groups of athletes' baseline performance were at a low level, which could be improved with or without strength training intervention. Conversely, the well-trained athletes had higher performance levels which required higher intensity or volume of the usual OTBS training to induce any form of improvement to OTBS performance. Therefore, the addition of strength training to the intervention groups of well-trained athletes resulted in significant beneficial effect.

Despite the nonsignificant effect in recreational and adolescent athletes, these athletes should be made aware that there would be a diminishing return in training effect from OTBS training alone as their training history increases..$^{58}$ In such a situation, the addition of strength training could further enhance their training adaptations and performance. In addition, strength training has been shown to reduce sports injuries and overuse injuries. ${ }^{59}$ Therefore, it is still recommended that recreational and adolescent athletes include strength training as part of their overall training program.

The studies included in the meta-analysis have used different modes of strength training to enhance OTBS performances. These included PT, HWT, EWT, and HPT. Although each mode of strength training has been shown to result in different neuromuscular adaptations, ${ }^{60}$ it has also been noted to result in similar improvement in strength and power in individuals with no strength training experience. ${ }^{61}$ The current meta-analysis showed that HWT resulted in a significant small effect on the improvement in OTBS time-trial performance, whereas there was no significant effect from PT, EWT, and HPT. This suggests that HWT may be the most effective form of strength training in improving OTBS time-trial performance. This only partially supports the findings of the systematic reviews by Berryman et $\mathrm{al}^{15}$ and Denadai et $\mathrm{al}^{16}$ as both studies also showed significant effect for PT. The systematic review by Yamato et $\mathrm{a}^{21}$ also showed that explosive resistance training was effective in improving cycling performance among different modes of strength training. Although the PT has been shown to improve endurance performance in other systematic reviews and meta-analysis, ${ }^{15,16,21}$ our meta-analysis only showed a trend for a large effect under PT (ES $=1.49, P=.09)$. That said, even if $P>.05$, an $\mathrm{ES}=1.49$ can be converted into an improvement in 43 percentile points, which is not negligible as far as coaches, athletes, and analysts is concerned. One possible reason for mixed findings can be due to the different performance measures analyzed in previous reviews and meta-analysis as compared with this study.

\section{The Effect of Age and Training Duration}

Meta-regression analyses were performed to consider the effects of participants' age and training duration. The age of participants and training duration have no significant impact on the effects of strength training on OTBS time-trial performance.

The current findings showed that age had no significant impact on the effects of strength training on OTBS time-trial performance. Age of subjects in the studies included in the meta-analysis ranged from 11.7 to 39 years old. The meta-analysis by Denedai et al ${ }^{16}$ was not able to determine if age was a factor that impacts the effect of strength training on running economy as there was a high confounding effect between age and training level. In another metaanalysis, Berryman et a ${ }^{15}$ were not able to test the effect of age due to the lack of participants within the required age groups. Studies that investigated the impact of age on strength adaptations after a period of strength training have shown no difference in strength gain between younger and older adults. ${ }^{62,63}$ This is possibly why the current meta-analysis showed that age had no significant impact on the effects of strength training on OTBS time-trial performance. Currently, no study has compared the impact of strength training on OTBS time-trial performance in athletes of different age groups. As such, further investigation on the impact of age on the effects of strength training on OTBS time-trial performance is required to provide a firm conclusion.

Previous meta-analysis on the effects of strength training on running economy by Denadai et a ${ }^{16}$ noted that 6 to 14 weeks of strength training was effective in improving economy in endurance runners, whereas 14 to 20 weeks of strength training would be required to enhance running economy of highly trained runners. In support of this, Berryman et al ${ }^{15}$ suggested that longer duration training protocols might be more beneficial for improving energy cost of movement. One possible reason could be that longer training duration might lead to higher magnitude of strength gain due to the higher accumulated volume of work. The increase strength gains further led to greater improvement in energy cost of movement. However, our data showed that training duration has no effect on time-trial performance of OTBS. This difference in findings could be due to the difference in the variables being assessed. Indeed, energy cost of movement is one of the factors affecting time-trial performance; nevertheless, it is not the only factor. For example, the improvement in strength could have allowed individuals to reduce the rate of fatigue, hence, allowing them to sustain high power output for a longer period of time. ${ }^{19}$ In summary, in our review we are focused on the main performance outcome (ie, time trial), whereas the other authors have been more focused on the performance determinants.

\section{Research Gaps}

Studies included in the meta-analysis were on endurance running, cycling, and swimming and rowing. There are currently a limited number of randomized controlled trial studies investigating the effects of strength training on rowing performance. In addition, there is no randomized controlled trial study on the effects of strength training on other time-based sports such as, for instance, kayaking and canoeing. Therefore, the results of this meta-analysis should not be generalized to other OTBS besides the ones reported in this study.

Future studies in this field should aim to compare the effects of different modes of strength training (isometric, isotonic, eccentric, variable resistance, and plyometric) on various OTBS time-trial performances. In addition, randomized controlled trial studies should provide a deeper insight of the deterministic or mechanistic relationship between neuromuscular adaptations and performance of different OTBS.

\section{Practical Applications}

Various strength training methods have been performed to enhance OTBS time-trial performance in running, cycling, and swimming and rowing. The current meta-analysis showed that strength 
training has a significant moderate effect on endurance performances with a meaningful impact on the percentile gain of ranked athletes.

There seems to be a greater beneficial effect from HWT compared with PT, EWT, and HPT. Studies that included HWT in the intervention had the participants performed heavy resistance exercise at 3- to 12-repetition-maximum load for 1 to 6 sets, and 2 to 3 times per week for 4 to 16 weeks. Therefore, practitioners should consider designing a similar training program.

Improvement in OTBS time-trial performances were independent of age, training status, and duration of intervention. Therefore, a 4 to 16 weeks strength training program should be able to result in improved performance in OTBS athletes regardless of age and training status.

\section{Conclusion}

Results from this meta-analysis supported a moderate beneficial effect of strength training on endurance performance. There seems to be a greater beneficial effect going under a HWT. Such improvements are not related to age of the participants, training status, or duration of the intervention.

\section{Acknowledgments}

No funding sources were dedicated to the preparation of this article. The authors have no conflicts of interest that are directly relevant to the content of this article.

\section{References}

1. Donato AJ, Tench K, Glueck DH, et al. Declines in physiological functional capacity with age: a longitudinal study in peak swimming performance. J Appl Physiol. 1985;94:764-769. doi:10.1152/ japplphysiol.00438.2002

2. Ingham S, Whyte G, Jones K, Nevill A. Determinants of $2000 \mathrm{~m}$ rowing ergometer performance in elite rowers. Eur J Appl Physiol. 2002;88: 243-246. PubMed ID: 12458367 doi:10.1007/s00421-002-0699-9

3. Joyner M, Coyle EF. Endurance exercise performance: the physiology of champions. J Physiol. 2008;586:35-44. PubMed ID: 17901124 doi:10.1113/jphysiol.2007.143834

4. Rabadan M, Diaz V, Calderon FJ, et al. Physiological determinants of speciality of elite middle- and long-distance runners. I Sports Sci. 2011; 29:975-982. PubMed ID: 21604227 doi:10.1080/02640414. 2011.571271

5. Conley DL, Krahenbuhl GS. Running economy and distance running performance of highly trained athletes. Med Sci Sports Exerc. 1980;12:357-360. PubMed ID: 7453514 doi:10.1249/00005768198025000-00010

6. Lucia A, Hoyos J, Perez M, et al. Inverse relationship between $\mathrm{VO}_{2} \mathrm{max}$ and economy/efficiency in world-class cyclists. Med Sci Sports Exerc. 2002;34:529-2084. PubMed ID: 12471319 doi:10. 1097/00005768-200203000-00021

7. Morgan DW, Craib M. Physiological aspects of running economy. Med Sci Sports Exerc. 1992;24:456-461. PubMed ID: 1560743

8. Blagrove RC, Howatson G, Hayes PR. Effects of strength training on the physiological determinants of middle- and long-distance running performance: a systematic review. Sports Med. 2018;48:1117-1149. PubMed ID: 29249083 doi:10.1007/s40279-017-0835-7

9. Foss $\varnothing$, Hallen J. Cadence and performance in elite cyclists. Eur $J$ Appl Physiol. 2005;93:453-462. PubMed ID: 15503124 doi:10.1007/ s00421-004-1226-y
10. Kjendlie P, Ingjer F, Stallman RK, Stray-Gundersen J. Factors affecting swimming economy in children and adults. Eur J Appl Physiol. 2004;93:65-74. PubMed ID: 15243747 doi:10.1007/ s00421-004-1164-8

11. Saunders PU, Pyne DB, Telford RD, Hawley JA. Factors affecting running economy in trained distance runners. Sports Med. 2004;34: 465-485. PubMed ID: 15233599 doi:10.2165/00007256-20043407000005

12. Sunde A, Støren $\varnothing$, Bjerkaas M, et al. Maximal strength training improves cycling economy in competitive cyclists. J Strength Cond Res. 2010;24:2157-2165. PubMed ID: 19855311 doi:10.1519/JSC. 0b013e3181aeb16a

13. Aagaard P, Andersen JL. Effects of strength training on endurance capacity in top-level endurance athletes. Scand J Med Sci Sports. 2010;20:39-47. PubMed ID: 20840561 doi:10.1111/j.1600-0838. 2010.01197.x

14. Amaro NM, Morouco PG, Marques MC, et al. A systematic review on dry-land strength and conditioning training on swimming performance. Sci Sports. 2019:34:e1-e4. doi:10.1016/j.scispo.2018.07.003

15. Berryman N, Mujika I, Arvisais D, Roubeix M. Strength training for middle- and long-distance performance: a meta-analysis. Int $J$ Sports Physiol Perform. 2018;13:57-63. doi:10.1123/ijspp.2017-0032

16. Denadai BS, de Aguiar RA, de Lima LCR, et al. Explosive training and heavy weight training are effective for improving running economy in endurance athletes: a systematic review and metaanalysis. Sports Med. 2017;47:545-554. PubMed ID: 27497600 doi:10.1007/s40279-016-0604-z

17. Gallagher D, Dipietro L, Visek AJ, et al. The effects of concurrent endurance and resistance training on 200-m rowing ergometer times in collegiate male rowers. J Strength Cond Res. 2010;24:1208-1214. PubMed ID: 20386119 doi:10.1519/JSC.0b013e3181d8331e

18. Lawton TW, Cronin JB, McGuigan MR. Strength testing and training of rowers. Sports Med. 2011;41:413-432. PubMed ID: 21510717 doi:10.2165/11588540-000000000-00000

19. Lum D, Tan F, Pang J, Barbosa TM. Effects of intermittent sprint and plyometric training on endurance running performance. $J$ Sport Health Sci. 2016. doi:10.1016/j.jbmt.2017.08.005

20. Pickett CW, Nosaka K, James Z, et al. Maximal upper-body strength and oxygen uptake are associated with performance in high-level 200-m sprint kayakers. J Strength Cond Res. 2018;32:3186-3192. PubMed ID: 29283928 doi:10.1519/JSC.0000000000002398

21. Yamato ML, Klau JF, Casa DJ, et al. The effects of resistance training on road cycling performance among highly trained cyclists: a systematic review. J Strength Cond Res. 2010;24:560-566. doi:10. 1519/JSC.0b013e3181c86583

22. Dumke CL, Prarrenroth CM, McBride JM, McCauley GO. Relationship between muscle strength, power and stiffness and running economy in trained male runners. Int J Sports Physiol Perfom. 2010; 5:249-261. doi:10.1123/ijspp.5.2.249

23. McKean MR, Burkett B. The influence of upper-body strength on flat-water sprint kayak performance in elite athletes. Int $J$ Sports Physiol Perform. 2014;9:707-714. doi:10.1123/ijspp.2013-0301

24. Stone MH, Sands WA, Carlock J, et al. The importance of isometric maximum strength and peak rate of force development in sprint cycling. J Strength Cond Res. 2004;18:878-884. PubMed ID: 15574097

25. van Someran KA, Howatson G. (2008). Prediction of flatwater kayaking performance. Int J Sports Physiol Perform. 2008;3: 207-218. doi:10.1123/ijspp.3.2.207

26. Aagaard P, Andersen JL, Bennekou M, et al. Effects of resistance training on endurance capacity and muscle fiber composition in young top-level cyclists. Scand J Med Sci Sports. 2011;21:e298- 
e307. PubMed ID: 21362056 doi:10.1111/j.1600-0838.2010. 01283.x

27. Amaro NM, Marinho DA, Marques MC, et al. Effects of dry-land strength and conditioning programs in age group swimmers. $J$ Strength Cond Res. 2017;31:2447-2454. PubMed ID: 28825604 doi:10.1519/JSC.0000000000001709

28. Girold S, Jalab C, Bernard O, et al. Dry-land strength training vs electrical stimulation in sprint swimming performance. J Strength Cond Res. 2012;26:497-505. PubMed ID: 22233789 doi:10.1519/ JSC.0b013e318220e6e 4

29. Paavolainen L, Häkkinen K, Hamäläinen I, et al. Explosive-strength training improves 5-km running time by improving running economy and muscle power. J Appl Physiol. 1999;86:1527-1533. PubMed ID: 10233114 doi:10.1152/jappl.1999.86.5.1527

30. Rønnestad BR, Hansen EA, Raastad T. In-season strength maintenance training increases well-trained cyclists' performance. Eur J Appl Physiol. 2010;110:1269-1282. doi:10.1007/s00421-010-1622-4

31. Allen SV, Hopkins WG. Age of peak competitive performance of elite athletes: a systematic review. Sports Med. 2015;45:1431-1441. PubMed ID: 26088954 doi:10.1007/s40279-015-0354-3

32. Maher CG, Sherrington C, Herbert RD, et al. Reliability of the PEDro scale for rating quality of randomized controlled trials. Phys Ther. 2003;83:713-721. PubMed ID: 12882612

33. Aspenes S, Kjendlie P, Hoff J, Helgerud J. Combined strength and endurance training in competitive swimmers. J Sports Sci Med. 2009;8:357-365. PubMed ID: 24149998

34. Bastiaans JJ, van Diemen ABJP, Veneberg T, Jeukendrup AE. The effects of replacing a portion of endurance training by explosive strength training on performance in trained cyclists. Eur J Appl Physiol. 2001;86:79-84. PubMed ID: 11820327 doi:10.1007/ s004210100507

35. Berryman N, Maurel D, Bosquet L. Effect of plyometric vs dynamic weight training on the energy cost of running. J Strength Cond Res. 2010;24:1818-1825. PubMed ID: 20543734 doi:10.1519/JSC. 0b013e3181def1f5

36. Bishop D, Jenkins DG, MacKinnon LT, et al. The effects of strength training on endurance performance and muscle characteristics. Med Sci Sports Exer. 1999;31:886-891. doi:10.1097/00005768199906000-00018

37. Bishop DC, Smith RJ, Smith MF, Rigby HE. Effect of plyometric training on swimming block start performance in adolescents. $J$ Strength Cond Res. 2009;23:2137-2143. PubMed ID: 19855343 doi: $10.1519 /$ JSC.0b013e3181b866d0

38. Cossor JM, Blanksby BA, Elliot BC. The influence of plyometric training on the freestyle tumble turn. J Sci Med Sport. 1999;2: 106-116. PubMed ID: 10476974 doi:10.1016/S1440-2440(99) 80190-X

39. Damasceno MV, Lima-Silva AE, Pasqua LA, et al. Effects of resistance training on neuromuscular characteristics and pacing during 10-km running time trial. Eur J Appl Physiol. 2015;115:15131522. PubMed ID: 25697149 doi:10.1007/s00421-015-3130-z

40. Garrido N, Marinho DA, Reis VM, et al. Does combined dry land strength and aerobic training inhibit performance of young competitive swimmers? J Sports Sci Med. 2010;9:300-310. PubMed ID: 24149700

41. Karsten B, Stevens L, Colpus M, et al. The effects of sportspecific maximal strength and conditioning training on critical velocity, anaerobic running distance, and $5-\mathrm{km}$ race performance. Int J Sports Physiol Perform. 2016;11:80-85. doi:10.1123/ijspp. 2014-0559

42. Kelly CM, Burnett AF, Newton MJ. The effect of strength training on three-kilometer performance in recreational women endurance runners. J Strength Cond Res. 2008;22:396-403. PubMed ID: 18550953 doi:10.1519/JSC.0b013e318163534a

43. Naczk M, Lopacinski A, Brzenczek-Owczarzak W, et al. Influence of short-term inertial training on swimming performance in young swimmers. Eur J Sport Sci. 2016;17:369-377. PubMed ID: 27760491 doi:10.1080/17461391.2016.1241304

44. Paton CD, Hopkins WG. Combining explosive and high-resistance training improves performance in competitive cyclists. $J$ Strength Cond Res. 2005;19:826-830. PubMed ID: 16287351

45. Pelligrino J, Ruby BC, Dumke CL. Effect of plyometrics on the energy cost of running and MHC and titin isoforms. Med Sci Sports Exerc. 2016;48:49-56. doi:10.1249/MSS.0000000000000747

46. Potdevin FJ, Alberty ME, Chevutschi A, et al. Effects of a 6-week plyometric training program on performance in pubescent swimmers. J Strength Cond Res. 2011;25:80-86. PubMed ID: 21157388 doi:10. 1519/JSC.0b013e3181fef720

47. Psilander N, Frank P, Flockhart M, Sahlin K. Adding strength to endurance training does not enhance aerobic capacity in cyclists. Scand J Med Sci Sports. 2015;25:e353-e359. PubMed ID: 25438613 doi: $10.1111 / \mathrm{sms} .12338$

48. Ramírez-Campillo R, Álvarez C, Henríquez-Olguín C, et al. Effects of plyometric training on endurance and explosive strength performance in competitive middle- and long-distance runners. $J$ Strength Cond Res. 2014;28:97-104. doi:10.1519/JSC.0b013e3182a1f44c

49. Rønnestad BR, Hansen EA, Raastad T. Effect of heavy strength training on thigh muscle cross-sectional area, performance determinants, and performance in well-trained cyclists. Eur J Appl Physiol. 2010;108:965-975. doi:10.1007/s00421-009-1307-z

50. Rønnestad BR, Hansen J, Nygaard H. 10 weeks of heavy strength training improves performance-related measurements in elite cyclists. $J$ Sports Sci. 2016;35:1435-1441. doi:10.1080/02640414.2016. 1215499

51. Schumann M, Mykkänen O, Doma K, et al. Effects of endurance training only versus same-session combined endurance and strength training on physical performance and serum hormone concentrations in recreational endurance runners. Appl Physiol Nutr Metab. 2015; 40:28-36. PubMed ID: 25494869 doi:10.1139/apnm-2014-0262

52. Vikmoen O, Ellefsen S, Trøen $\emptyset$, et al. Strength training improves cycling performance, fractional utilization of $\mathrm{VO}_{2}$ max and cycling economy in female cyclists. Scand J Med Sci Sports. 2016;26:384396. PubMed ID: 25892654 doi:10.1111/sms.12468

53. Vikmoen O, Rønnestad BR, Ellefsen S, Raastad T. Heavy strength training improves running and cycling performance following prolonged submaximal work in well-trained female athletes. Physiol Rep. 2017;5:e13149-14. doi:10.14814/phy2.13149

54. Vorup J, Tybirk J, Gunnarsson TP, et al. Effect of speed endurance and strength training on performance, running economy and muscular adaptations in endurance-trained runners. Eur J Appl Physiol. 2016;116: 1331-1341. PubMed ID: 27179795 doi:10.1007/s00421-016-3356-4

55. Higgins JP, Thompson SG, Deeks JJ, Altman DG. Measuring inconsistency in meta-analyses. BMJ. 2003;327:557-560. PubMed ID: 12958120 doi: $10.1136 / \mathrm{bmj} .327 .7414 .557$

56. Cohen J. Statistical Power Analysis for the Behavioral Sciences. 2nd ed. Hillsdale, NJ: Lawrence Erlbaum; 1988.

57. Bucheit M. Chasing the 0.2. Int J Sports Physiol Perform. 2016; 11:417-418. doi:10.1123/ijspp.2016-0220

58. Jones AM, Carter H. The effect of endurance training on parameters of aerobic fitness. Sports Med. 2000;29:373-386. PubMed ID: 10870864 doi:10.2165/00007256-200029060-00001

59. Lauersen JB, Bertelsen DM, Andersen LB. The effectiveness of exercise interventions to prevent sports injuries: a systematic review and meta-analysis of randomised controlled trials. Br J Sports Med. 
2014;48:871-877. PubMed ID: 24100287 doi:10.1136/bjsports2013-092538

60. Suchomel TJ, Nimphius S, Bellon CR, Stone MH. The importance of muscular strength: training considerations. Sports Med. 2018; 48:765-785. PubMed ID: 29372481 doi:10.1007/s40279-018-0862-z

61. Cormie P, McGuigan MR, Newton RU. Adaptations in athletic performance after ballistic power versus strength training. Med Sci Sports Exerc. 2010;42:1582-1598. doi:10.1249/MSS. 0b013e3181d2013a
62. Häkkinen K, Newton RU, Gordon SE, et al. Changes in muscle morphology, electromyographic activity, and force production characteristics during progressive strength training in young and older men. J Gerontol. 1998;53A:B415-B423. doi:10.1093/gerona/53A. 6.B415

63. Martel GF, Roth SM, Ivey FM, et al. Age and sex affect human muscle fibre adaptations to heavy-resistance strength training. Exp Physiol. 2006;91:457-464. PubMed ID: 16407471 doi:10.1113/ expphysiol.2005.032771 
Copyright of International Journal of Sports Physiology \& Performance is the property of Human Kinetics Publishers, Inc. and its content may not be copied or emailed to multiple sites or posted to a listserv without the copyright holder's express written permission.

However, users may print, download, or email articles for individual use. 